This is a post-peer-review, pre-copyedit version of an article published in Journal of Electronic Materials. The final authenticated version is available online at:

https://doi.org/10.1007/s11664-020-08015-y

\title{
Influence of temperature and aging on the thermal contact resistance in thermoelectric devices
}

\author{
A. Rodríguez*, G. Pérez-Artieda, I. Beisti, D. Astrain, A. Martínez \\ Department of Mechanical Engineering. ISC - Institute of Smart Cities \\ Public University of Navarre, UPNa. Pamplona SPAIN. \\ *Tel: +34 948 169295, Fax: +34 948 169099, e-mail: antonio.rodriguez@unavarra.es
}

\begin{abstract}
In the first phases of the development of thermoelectric systems, such as the thermoelectric generators, when the thermal design is carried out, the most important parameters affecting the performance are the thermal resistances of the components. This paper focusses on the thermal contact resistance (TCR), analyzing the influence of aging and temperature on different thermal interface materials (TIM), i.e., thermal paste, graphite and indium. In previous papers, TCR has been studied depending on parameters such as surface roughness, bonding pressure, thermal conductivity and surface hardness. However, in thermoelectric applications, a relevant aspect to consider when choosing a TIM is aging due to thermal stress. The exposure of this type of materials to high temperatures for long periods of time leads to deterioration, which causes an increase in the thermal contact resistance which impairs the conduction of the heat flow. Therefore, there is a need to study the behavior of thermal interface materials exposed to temperatures typical in thermoelectric generators, to make a correct selection of the TIM. It has been observed that exposure temperatures of around $180{ }^{\circ} \mathrm{C}$ induce a significant increase in the thermal impedance of the three TIM's under study, although this effect is much more relevant for the thermal paste. The contact comprising steel, thermal paste and ceramic presents a $300 \%$ increase in the thermal impedance after 70 days of aging, whereas that exceeds $185 \%$ for the contact of aluminum, thermal paste and ceramic. In the tests with exposure temperature of $60^{\circ} \mathrm{C}$, there is no observed decrease in the thermal impedance.
\end{abstract}

Keywords: Thermal contact resistance, Thermoelectric devices, Thermal interface material, Thermal aging, Ceramic steel contact, Ceramic aluminum contact.

\section{Nomenclature}

$\Delta \mathrm{T} \quad$ Temperature difference between the fluxmeter surfaces in contact with the sample $\left[{ }^{\circ} \mathrm{C}\right]$

1 A cross-sectional area of fluxmeter $\left[\mathrm{m}^{2}\right]$

$2 \mathrm{k}_{\mathrm{A}} \quad$ Aluminum thermal conductivity $\left[\mathrm{W} / \mathrm{m}^{\circ} \mathrm{C}\right]$

$3 \quad \mathrm{k}_{\mathrm{C}} \quad$ Ceramic thermal conductivity $\left[\mathrm{W} / \mathrm{m}{ }^{\circ} \mathrm{C}\right]$

$4 \mathrm{k}_{\text {fluxmeter }}$ fluxmeter thermal conductivity $\left[\mathrm{W} / \mathrm{m}{ }^{\circ} \mathrm{C}\right]$

5 ks Steel thermal conductivity $\left[\mathrm{W} / \mathrm{m}{ }^{\circ} \mathrm{C}\right]$

$36 \quad \mathrm{~L}_{\mathrm{A}} \quad$ Aluminum thickness $[\mathrm{m}]$

$7 \quad \mathrm{~L}_{\mathrm{c}} \quad$ Ceramic thickness $[\mathrm{m}]$

$8 \mathrm{~L}_{\mathrm{i}} \quad$ sensors position in the fluxmeter " $\mathrm{i}=1$ to 4 " $[\mathrm{m}]$

9 Ls Steel thickness [m]

$\quad \dot{Q}$ heat flow through the contact between fluxmeters [W]

1 R $\mathrm{R}_{\mathrm{c}} \quad$ Thermal contact resistance, TCR $\left[{ }^{\circ} \mathrm{Cm}^{2} / \mathrm{W}\right]$

$2 \mathrm{~T}_{\mathrm{av}} \quad$ Average sample temperature during the tests $\left[{ }^{\circ} \mathrm{C}\right]$

$3 \mathrm{~T}_{\mathrm{i}}$ Temperature sensors in the fluxmeter " $\mathrm{i}=1$ to 6 " $\left[{ }^{\circ} \mathrm{C}\right]$

$44 \quad \mathrm{~T}_{3}, \quad$ Bottom fluxmeter temperature in contact with the sample $\left[{ }^{\circ} \mathrm{C}\right]$ 
$46 \mathrm{u}(\mathrm{Zg}) \quad$ uncertainty of Global thermal impedance $\left[{ }^{\circ} \mathrm{Cm}^{2} / \mathrm{W}\right]$

$47 \mathrm{u}\left(\mathrm{T}_{\mathrm{i}}\right) \quad$ uncertainty of temperature sensors in the fluxmeter " $\mathrm{i}=1$ to 6 " $\left[{ }^{\circ} \mathrm{C}\right]$

$48 \mathrm{u}\left(\mathrm{L}_{\mathrm{i}}\right) \quad$ uncertainty of sensors position in the fluxmeter " $\mathrm{i}=1$ to 4 " $[\mathrm{m}]$

$49 \mathrm{u}(\dot{\mathrm{Q}}) \quad$ uncertainty of heat flow through the contact between fluxmeters [W]

$50 \quad Z_{\mathrm{k}} \quad$ Thermal impedance due to the conductivity, $\left[{ }^{\circ} \mathrm{Cm}^{2} / \mathrm{W}\right]$

$51 \quad Z_{\mathrm{g}} \quad$ Global thermal impedance of the sample, $\left[{ }^{\circ} \mathrm{Cm}^{2} / \mathrm{W}\right]$

52

\section{INTRODUCTION}

54 The development of thermoelectric applications requires adequate thermal designs to guarantee efficient operation. Specifically, the thermal resistance of all the components must be optimized. In this regard, the thermal contact resistances (TCR) between all the components must be as low as possible, that being the reason why thermal interface materials (TIMs) are used. Unfortunately, aging of TIMs is proven to increase the TCRs, which impairs the heat transfer between the thermoelectric modules and the heat exchangers, causing a decrease in the performance of the thermoelectric application.

The use of TIMs to reduce TCRs has been studied thoroughly in the field of electronics, as can be seen in the reviews presented in [1], [2], [3]. In addition, reference [4] presents a study on TIMs for high performance flip-chip-ball-grid arrays (HFCBGAs), whereas [5] conducts so for insulated gate bipolar transistors (IGBTs). Likewise, reference [6] summarizes the research on TIM reliability, with special interest in methodologies and results of several testing procedures. Complementary, there are studies of aging due to radiation on electronics for space applications [7], and studies on the effect of aging of TIMs in power electronics subjected to either thermal cycling [8-9] or isothermal [10] conditions. standard method [11]. The literature presents several examples of them, such as that described in [12], which uses a screw to apply pressure and cotton as insulator; or the one introduced in [13], which is used to measure the thermal contact conductance (TCC) of structural materials. More interesting is the bench described in [14], in which the applied pressure is controlled by a computer-based algorithm, and a vacuum chamber is used to remove convection losses. The TCR is obtained through the calculation of the temperature-dependent thermal conductivity of the rods used for determination of the heat flow. 
Furthermore, a technical review of characterization methods of TCRs in TIMs can be found in [15]. Recently, a review of the performance and characterization of TIMs for electronic applications is available in [16].

However, aging of TIMs has been scarcely studied in thermoelectric applications [17], despite its huge impact on the final efficiency of these systems. This is the main goal of this paper. The knowledge on the TIM performance (that is, its influence on the TCR) for long periods at high temperatures is essential to ensure the efficient performance of a thermoelectric system over its working life. The selection of the best TIM for each application would lead to reductions in both maintenance and economic cost.

To fulfill this goal, the test bench presented in this paper has been developed and tested. This bench was designed specifically for thermoelectric applications. It allows the calculation of TCR of several TIMs depending on the temperature and pressure, including also the effect to aging. The test bench is presented in the following section; then, the measurement methodology for TCR characterization is introduced, along with the aging protocol. After that, the experimental results on the evolution of TCRs are described; and finally, some conclusions and perspectives are presented.

\section{EXPERIMENTAL SET-UP}

An original experimental steady-state test bench has been designed and constructed, which can be seen in Fig.1. It is installed inside an environmental chamber with controlled temperature and humidity (60\% in all the tests), wherein the air can be considered to have zero velocity. The test bench comprises two solid blocks (called fluxmeters) between which the TIM is placed, a heat source installed at the bottom, and a forced-convection heat sink at the top. Heat is forced to flow through the fluxmeters and the sample, while the pressure between them is controlled. The heat source is composed of four electric cartridges inserted in a solid piece of steel, providing up to $400 \mathrm{~W}$ (100 W per cartridge). Finally, the fluxmeters are made of 304 AISI INOX steel. They have presented no significant variation in their thermal conductivity along the tests.

The fluxmeter at the bottom connects the heat source and the sample, and has a base area of $40 \mathrm{x} 40 \mathrm{~mm}^{2}$, similar to that of the sample and also to that presented by common thermoelectric modules. The fluxmeter at the top presents also $40 \times 40 \mathrm{~mm}^{2}$ of base area and connects the sample and the heat sink. The heat sink is made of $6063 \mathrm{~T} 5$ aluminum, presents base area of 150x150 $\mathrm{mm}^{2}$ and $10 \mathrm{~mm}$ of base height, and includes fins of $30 \mathrm{~mm}$ in height and $1.5 \mathrm{~mm}$ in thickness separated $3 \mathrm{~mm}$, and a fan to produce forced convection. Given that the exposed surfaces of the test bench (fluxmeters and sample) are covered by a thick layer of 
insulator (see Fig. 2), the heat flow can be considered unidimensional, flowing through the fluxmeter, the sample and the heatsink.

Six Pt-100 temperature probes (model FPA15L0100, with measuring range from $-50^{\circ} \mathrm{C}$ to $500^{\circ} \mathrm{C}$, uncertainty of $0.1^{\circ} \mathrm{C}$, and diameter of $1.5 \mathrm{~mm}$ ), are inserted in holes made on the fluxmeters, which present diameter of $1.75 \mathrm{~mm}$ and depth of $20 \mathrm{~mm}$ (see Fig. 3). An additional probe measures the ambient temperature. The uncertainties associated to the temperatures, lengths and diameters were calculated in the calibration laboratory Applus + AC6, located in Navarre (Spain).

The bench includes the linear actuator RCP2-RA10C (built by IAI AMERICA), which presents a capacity of up to $6 \mathrm{kN}$. It allows to perform the tests with the assembly pressure recommended by the manufacturers of thermoelectric modules. The pressure sensor K-1613 (LORENZ MESSTECHNIK), with an upper limit of $10 \mathrm{kN}$, allows the measurement of the tension to which the sample is subjected and the control of the force of the actuator, to ensure that the sample is at the desired pressure. All data is recorded with an ALMEMO 5690-2M09TG3 connected to a personal computer.

The accuracy in the measurement depends on the precise account of the heat flowing through the sample, so heat losses must be minimized. To do so, the upper and lateral sides of the fluxmeters are insulated with two layers of insulation material (an inner layer of rock wool and an outer layer of neoprene).

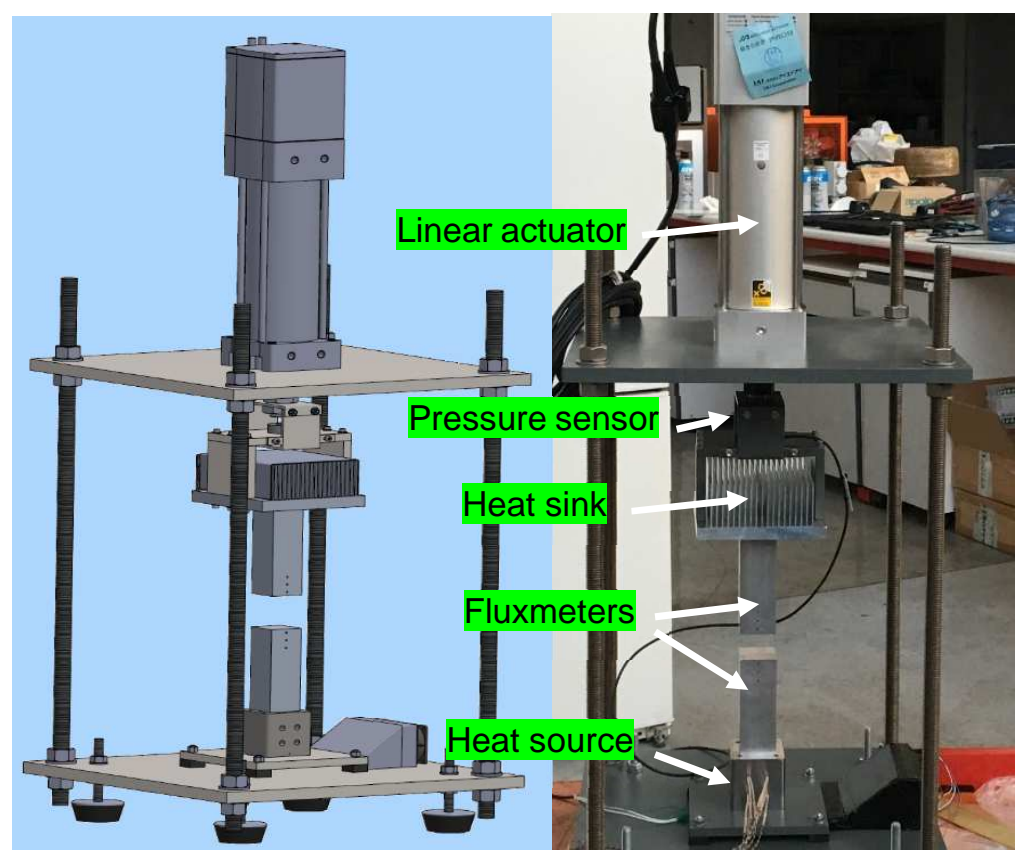

Fig.1. Test bench 


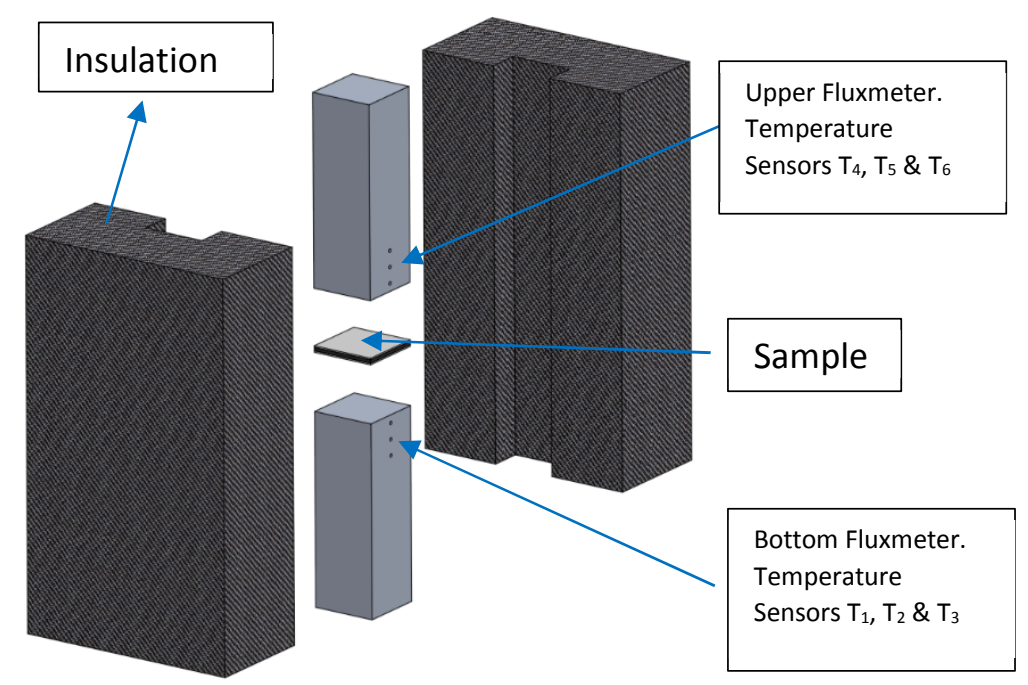

Fig. 2. Position of temperature sensors and fluxmeter insulator

123 Previous works of our research group, both on thermoelectric refrigeration [18] and thermoelectric power generation [19], [20], [21], made evident that a precise characterization of the TIM is required in thermoelectric systems. To describe the thermal characterization method and further selection of the TIM, the conditions described in [19] have been adopted. That paper presents a real thermoelectric generator that harvest heat from the hot gases in a chimney, as can be seen in Fig. 3. Several thermoelectric modules (with outer layer of ceramic material) are installed between the hot surface of the chimney (made of steel) and the heat sinks (made of aluminum). TIMs are installed to improve the contact between them. Therefore, two different testing configurations arise from this application: steel (base area of $40 \times 40 \mathrm{~mm}^{2}$, thickness of $4.5 \mathrm{~mm}, \mathrm{ks}_{\mathrm{S}}$ of $16 \mathrm{~W} / \mathrm{m}^{\circ} \mathrm{C}$ ) and a layer of $\mathrm{Al}_{2} \mathrm{O}_{3}$ ceramic, Alumina 96\% PER MI 866-1005 Marlow Industries, inc. (base area of 40x40 $\mathrm{mm}^{2}$, thickness of $0.75 \mathrm{~mm}, \mathrm{k}_{\mathrm{C}}$ of $35 \mathrm{~W} / \mathrm{m}^{\circ} \mathrm{C}$ ) connected by a TIM. This assembly represents the contact between the chimney and the hot face of a thermoelectric module.

- $\quad$ CERAMIC-TIM-ALUMINUM, (C-TIM-A): The sample is a sandwich composed of a layer of 6063-T5 aluminum (base area of $40 \times 40 \mathrm{~mm}^{2}$, thickness of $10 \mathrm{~mm}, \mathrm{k}_{\mathrm{A}}$ of $196 \mathrm{~W} /{ }^{\circ} \mathrm{C}$ ) and a layer of $\mathrm{Al}_{2} \mathrm{O}_{3}$, with a TIM between them. This assembly represents the contact between the cold face of a thermoelectric module and the heat sink. 
Three different TIMs are studied for both configurations:

- Graphite pad HT2505 (G) (GrafTech International Holdings Inc).

- Phase Change Material, Indium (I). KITEA-85553 Indium Corporation.

- Polysynthetic oils thermal grease Artic Silver 5, which contains micronized silver, sub-micron zinc oxide, aluminum oxide and boron nitride particles $(\mathrm{P})$.

The expected aging due to thermal stress in a TIM is an aspect to consider when choosing the TIM for a specific thermoelectric application. Aging causes a deterioration of the material, with an increase in its thermal contact resistance that impairs the heat conduction. Therefore, it is necessary to study the performance of these materials at high temperatures for long periods of time.

Most of TIMs in the literature are used for heat dissipation in electronic devices, whose maximum temperature hardly exceeds $100^{\circ} \mathrm{C}$. However, in thermoelectric applications, especially in electric power generation, higher temperatures are reached, as occurs in the application presented in this paper, where the temperature of the outer surface of the chimney lies around $180^{\circ} \mathrm{C}$. Consequently, $180^{\circ} \mathrm{C}$ is selected as aging temperature for the TIM in contact with the chimney. Similarly, $60^{\circ} \mathrm{C}$ is selected as aging temperature for the TIM in contact with the heat sink, as lower temperatures are expected in this component. The aging process is conducted in two ovens that maintain the temperature constant at $60^{\circ} \mathrm{C}$ and $180^{\circ} \mathrm{C}$ respectively. Therefore, as two aging temperatures have been tested for three different TIMs in two configurations, a total of 12 studies have been conducted.

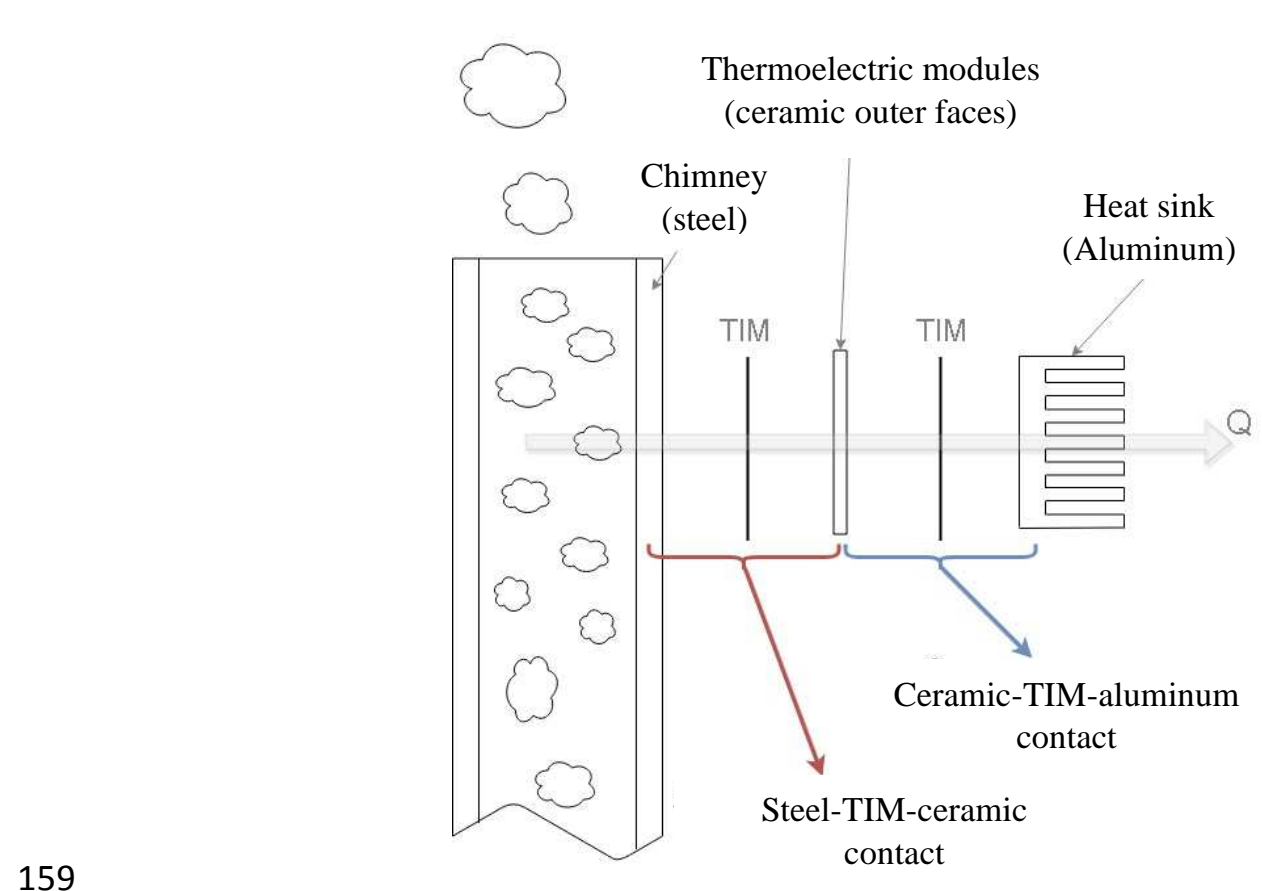

Fig. 3. Scheme of the contacts in a thermoelectric generator 
161 A specific configuration has been used for each contact, as can be seen in Fig. 4. In steady state, the global

162

163

164

165

166

167

168

169

170

171

172

173

174

175

176

177

178

179 thermal impedance $\mathrm{Zg}$ is defined as the temperature gradient between the faces of the fluxmeters in contact with the sample, per unit of heat flux passing thorough the interface area, $(\dot{Q} / \mathrm{A})$.

$Z_{g}=\Delta T /(\dot{Q} / A)$

The term $\Delta \mathrm{T}\left(=\mathrm{T}^{\prime}{ }^{\prime}-\mathrm{T}^{\prime}\right)$ is the temperature difference between the surfaces of the fluxmeters. These temperatures are obtained by extrapolation from the temperatures measured by the probes located along the fluxmeters when the thermal equilibrium is reached, according to Eqs. 2 and 3.

$T_{3^{\prime}}=\frac{L_{2}}{L_{1}} T_{3}+\left(1-\frac{L_{2}}{L_{1}}\right) T_{1}$

$T_{4^{\prime}}=\frac{L_{4}}{L_{3}} T_{4}+\left(1-\frac{L_{4}}{L_{3}}\right) T_{6}$

Heat is supplied at one end (generator, heat source) and dissipated at the other (heat sink), as Fig. 1 displays.

With the adequate insulation, the heat flow can be quantified as the thermal energy produced in the generator minus the thermal energy that leaks through the insulator (see Fig. 2). The heat flow through fluxmeter at the bottom has two terms: the leaks plus the heat flowing through the sample. Considering that the sample is thin, and the sides are well insulated, the heat flowing through the sample is equal to that flowing through the fluxmeter at the top. Therefore, by knowing the thermal conductivity of the fluxmeter and the temperatures measured by T4 and T6, (whose separation is precisely known), we can determine the heat flux passing thorough the interface area $(\dot{Q})$ with Eq. (4).

$\dot{Q}=k_{\text {fluxmeter }} \frac{T_{4}-T_{6}}{A * L_{3}}$

The thermal conductivity of the fluxmeter (AISI-304 stainless steel) used to calculate the heat flux was taken at the average temperature between the sensors T4 and T6. The temperature-dependent thermal conductivity is obtained from [22]. 


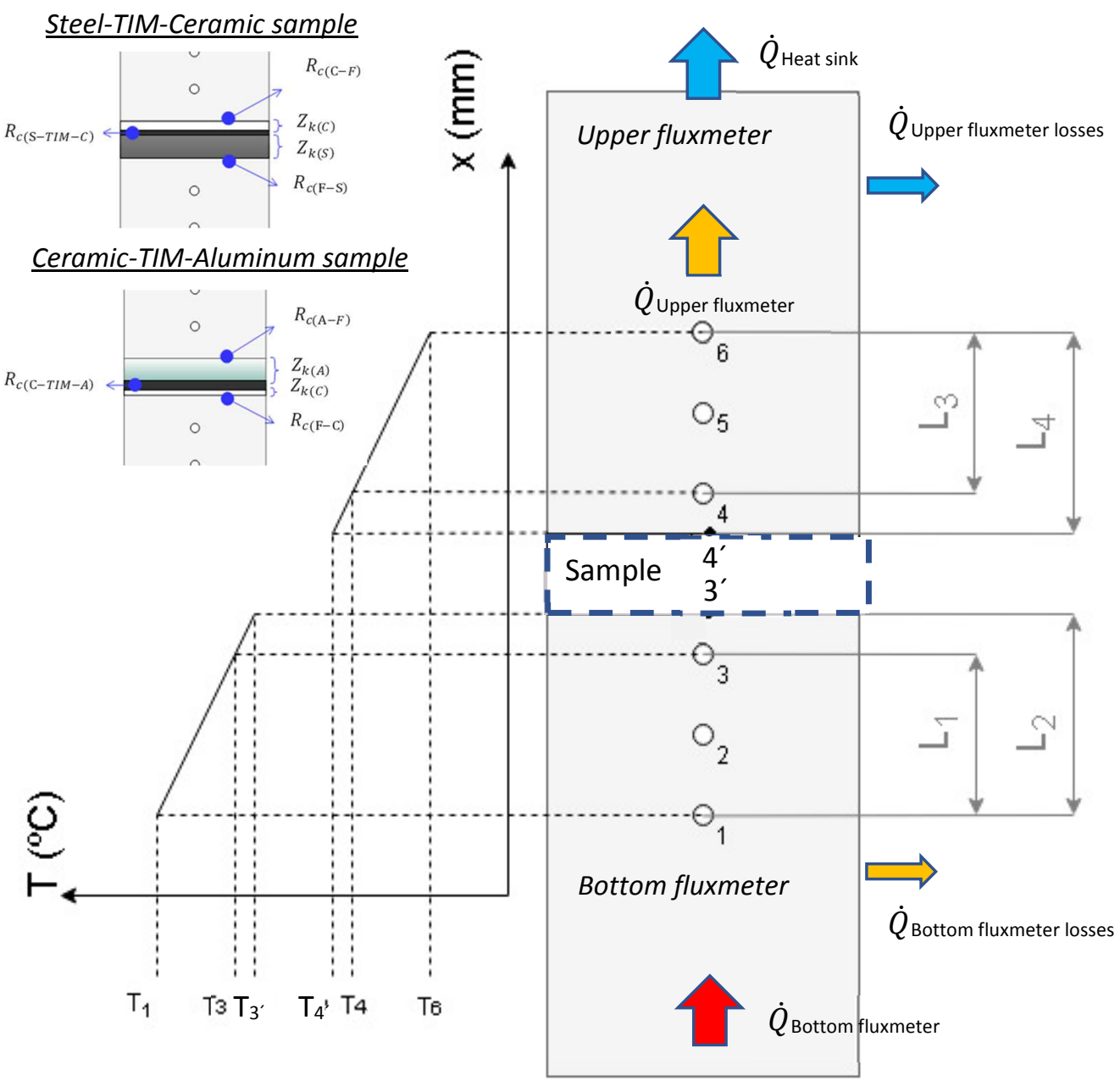

Fig. 4. Configurations for the contacts and temperature sensors. Thermal and heat flux distribution.

184 Figure 4 shows the configuration of the two contacts and the thermal impedances that come from them.

The global thermal impedance in the case of the steel-ceramic contact $\mathrm{Z}_{\mathrm{g} \text { (S-TIM-C) }}$ is composed of the conductive thermal impedances of the ceramic material $\left(\mathrm{Z}_{\mathrm{k}(\mathrm{C})}\right)$ and steel $\left(\mathrm{Z}_{\mathrm{k}(\mathrm{S})}\right)$, along with three thermal contact resistances: two due to the thermal contact resistances between the fluxmeters and the sample,

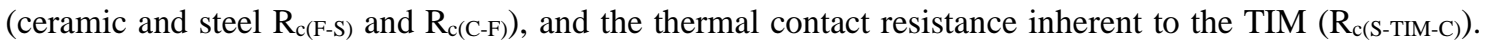
The calculation of the global thermal impedance in the case of aluminum-contact, $\mathrm{Zg}_{(\mathrm{S}-\mathrm{TIM}-\mathrm{C}) \text {, is similar but }}$ substituting steel for aluminum.

191 The global thermal impedance of the Steel-TIM-Ceramic sample presents the following expression:

$Z_{g(S-T I M-C)}=R_{C(F-S)}+Z_{k(S)}+R_{c(S-T I M-C)}+Z_{k(C)}+R_{C(C-F)}$

And the global thermal impedance of the Ceramic-TIM-Aluminum sample is: 
195 The thermal impedance for the layers of aluminum, steel and ceramic are respectively:

$196 \quad Z_{k(A)}=\frac{L_{A}}{k_{A}}$

$197 \quad Z_{k(S)}=\frac{L_{S}}{k_{S}}$

$198 \quad Z_{k(C)}=\frac{L_{C}}{k_{C}}$

In our research, these impedances result to be $Z_{k(A)}=0.509 \times 10^{-4} \mathrm{~m}^{2}{ }^{\circ} \mathrm{C} / \mathrm{W} ; Z_{k(S)}=2.81 \times 10^{-4} \mathrm{~m}^{2}{ }^{\circ} \mathrm{C} / \mathrm{W} ; Z_{k}(\mathrm{~A})$ $=0.214 \times 10^{-4} \mathrm{~m}^{2}{ }^{\circ} \mathrm{C} / \mathrm{W} ;$

201

The thermal contact resistances between the fluxmeters and the ceramic-TIM-steel sample $\left(\mathrm{R}_{\mathrm{c}(\mathrm{F}-\mathrm{S})}\right.$ and $\mathrm{R}_{\mathrm{c}(\mathrm{C}-\mathrm{-}}$

F) ), as well as those between the fluxmeters and the ceramic-TIM-aluminum sample $\left(R_{c(A-F)}\right.$ and $\left.R_{C(F-C)}\right)$, are calculated prior to performing the tests. In all the cases, we have assumed that these values do not change due to the use of fresh graphite pads, and therefore these contacts do not suffer aging. The thermal contact resistances between the fluxmeters and the samples turn out to be $R_{\mathrm{c}(\mathrm{F}-\mathrm{S})}=0.535 \times 10^{-4} \mathrm{~m}^{2 \circ} \mathrm{C} / \mathrm{W} ; \mathrm{R}_{\mathrm{c}(\mathrm{C}-}$ ${ }_{\mathrm{F})}=\mathrm{R}_{\mathrm{C}(\mathrm{F}-\mathrm{C})}=0.576 \times 10^{-4} \mathrm{~m}^{20} \mathrm{C} / \mathrm{W} ; \mathrm{R}_{\mathrm{C}(\mathrm{A}-\mathrm{F})}=0.438 \times 10^{-4} \mathrm{~m}^{2 \circ} \mathrm{C} / \mathrm{W}$.

The thermal contact resistance of the TIM ( $\left.\mathrm{R}_{\mathrm{c}\left(-\mathrm{TIM}_{-}\right)}\right)$is the only term of the global thermal impedance $\mathrm{Zg}$ that is affected by the aging process. Therefore, the variation in the global thermal impedance due to aging shows the trend in the thermal contact resistance of the TIM.

The testing protocol includes, in the first place, the assembly of the sample (TIM, ceramic plate and steel or aluminum block), as can be seen in Fig. 5, which is then installed between the fluxmeters.

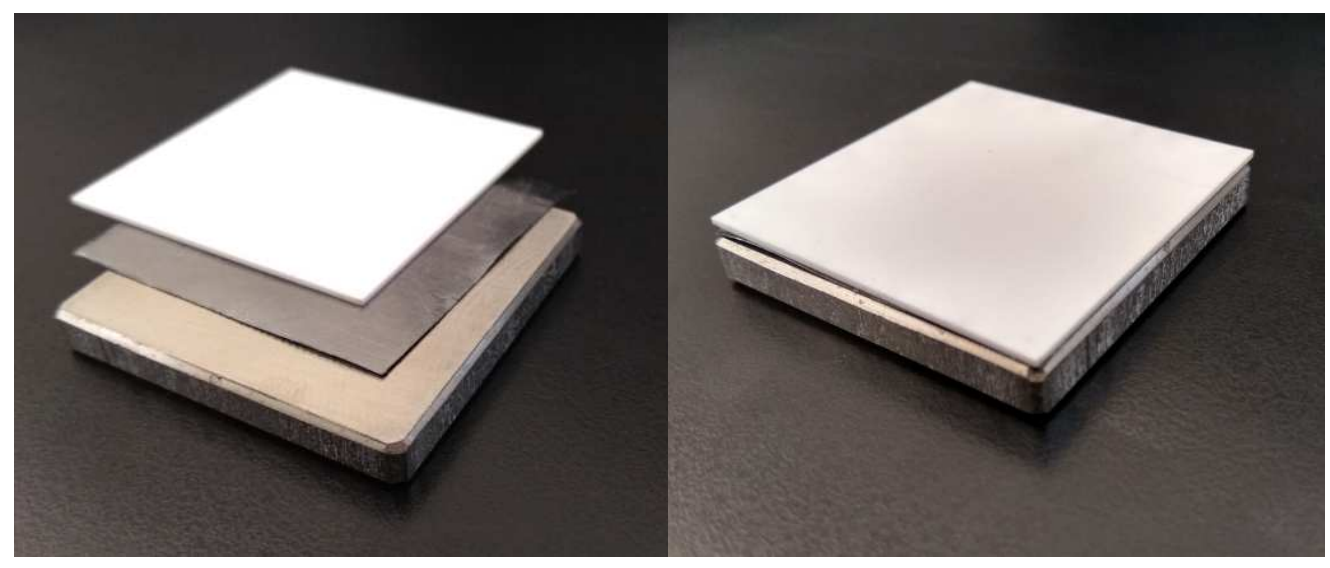

Fig. 5. Assembly of Steel-graphite-ceramic sample 

flow. The data provided by the temperature and pressure sensors is monitored in real time, as can be seen in Fig. 6 and Fig. 7. Therefore, when temperatures reach the steady state, the actuator is activated to apply the required pressure. It is important to do this step after the complete stabilization of the temperatures, to ensure the complete dilatation of all the components. Finally, once both the pressure and the temperatures are stable again, the data is recorded.

After the first test, the samples are introduced in the corresponding oven to start the aging process. The samples with the TIM remain in the oven for 70 days (1680 hours). Within that period, the tests are conducted every 20 days. Every sample is taken from the oven and installed in the test bench. Once it reaches room temperature, heat flow is generated until the average temperature $T_{a v}$ between $T_{3}$ and $T_{4}$ lies between $97{ }^{\circ} \mathrm{C}$ and $103{ }^{\circ} \mathrm{C}$. The temperature evolution during this process is shown in Fig. 6 . This average temperature is equal in all the tests, in order to obtain comparable results.

227 The thermoelectric modules used in our previous works are Marlow TG12-6, which are recommended to operate under a pressure of $1.4 \mathrm{MPa}$. This is the pressure applied in all the tests. In the oven, no pressure was applied to the samples.

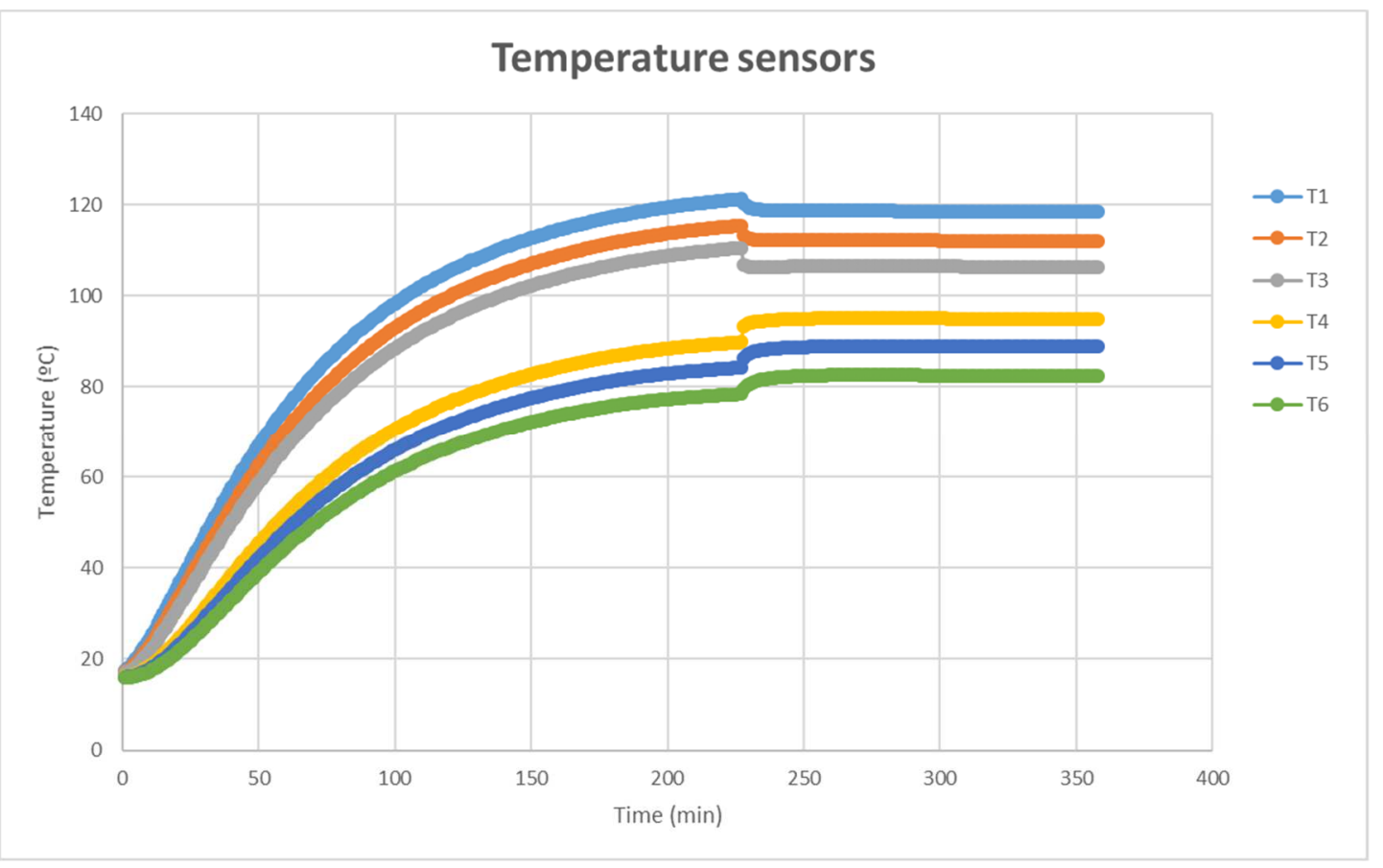




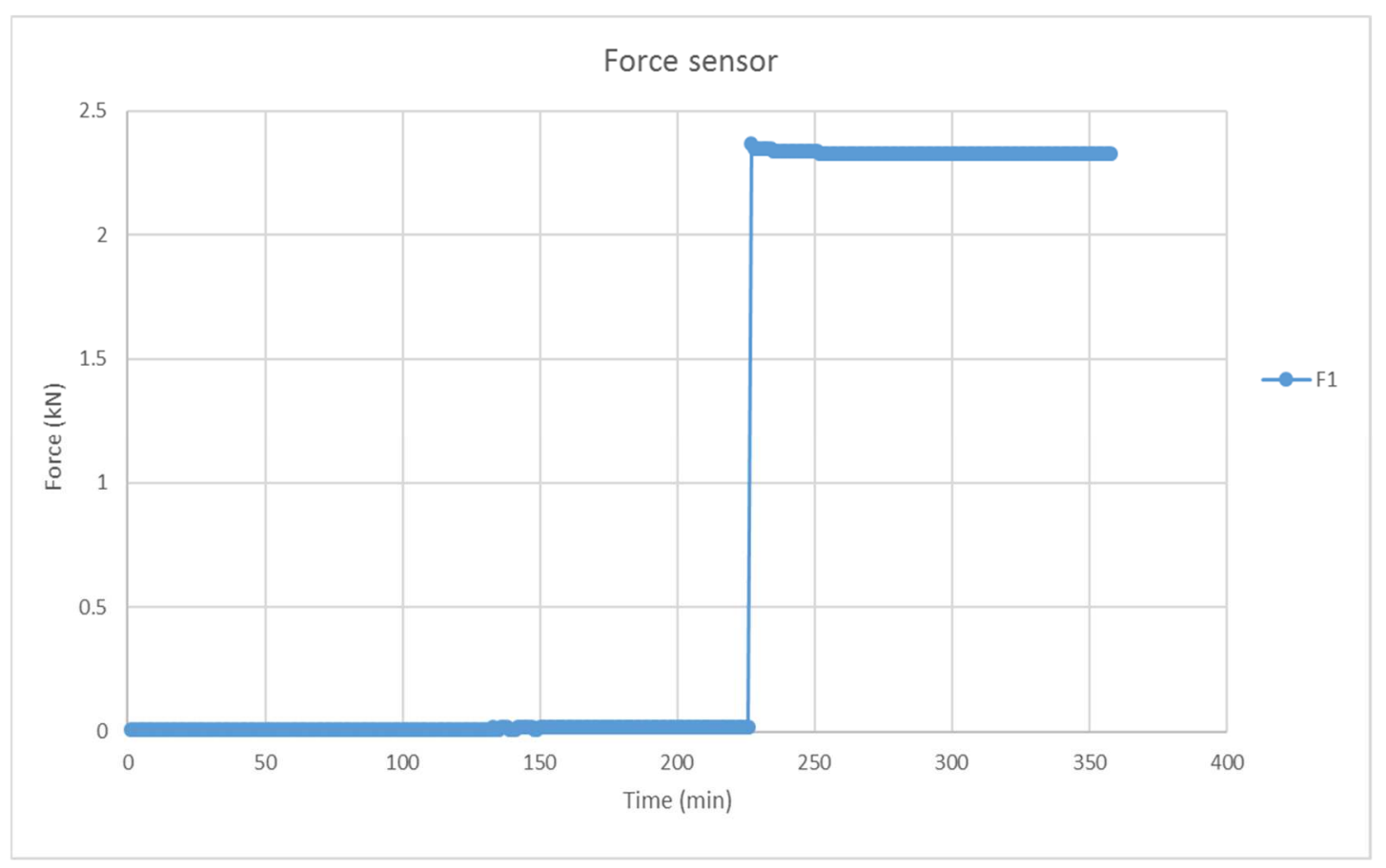

233

Fig. 7. Force sensor monitored in real time, testS-G-C_60 (aging of 20 days)

234

$$
\mathrm{Z}_{g}=\mathrm{A}\left(\frac{T_{1}}{\dot{Q}}-\frac{L_{2}}{L_{1}} \frac{T_{1}}{\dot{Q}}+\frac{L_{2}}{L_{1}} \frac{T_{3}}{\dot{Q}}-\frac{T_{6}}{\dot{Q}}+\frac{L_{4}}{L_{3}} \frac{T_{6}}{\dot{Q}}-\frac{L_{4}}{L_{3}} \frac{T_{4}}{\dot{Q}}\right)
$$

Then, eq. 12 provides the uncertainty in the measurement of the global thermal impedance, wherein the uncertainties associated to temperatures and lengths were calculated in a calibration laboratory (Applus + AC6, Navarre, Spain).

$$
\begin{aligned}
& {\left[\frac{L_{2}\left(T_{1}-T_{3}\right)}{L_{1}^{2} \cdot \dot{Q}}\right]^{2} u^{2}\left(L_{1}\right)+\left[\frac{T_{3}-T_{1}}{L_{1} \cdot \dot{Q}}\right]^{2} u^{2}\left(L_{2}\right)+\left[\frac{1}{\dot{Q}}-\frac{L_{2}}{L_{1} \cdot \dot{Q}}\right]^{2} u^{2}\left(T_{1}\right)+\left[\frac{L_{2}}{L_{1} \cdot \dot{Q}}\right]^{2} u^{2}\left(T_{3}\right)+} \\
& u\left(\mathrm{Z}_{g}\right)=\mathrm{A}\left[\left[\frac{L_{4}\left(T_{6}-T_{4}\right)}{L_{3}^{2} \cdot \dot{Q}}\right]^{2} u^{2}\left(L_{3}\right)+\left[\frac{T_{6}-T_{4}}{L_{3} \cdot \dot{Q}}\right]^{2} u^{2}\left(L_{4}\right)+\left[-\frac{L_{4}}{L_{3} \cdot \dot{Q}}\right]^{2} u^{2}\left(T_{4}\right)+\left[-\frac{1}{\dot{Q}}+\frac{L_{4}}{L_{3} \cdot \dot{Q}}\right]^{2} u^{2}\left(T_{6}\right)+\right. \\
& +\left[-\frac{T_{1}}{\dot{Q}^{2}}+\frac{L_{2}}{L_{1}} \frac{T_{1}}{\dot{Q}^{2}}-\frac{L_{2}}{L_{1}} \frac{T_{3}}{\dot{Q}^{2}}+\frac{T_{6}}{\dot{Q}^{2}}-\frac{L_{4}}{L_{3}} \frac{T_{6}}{\dot{Q}^{2}}+\frac{L_{4}}{L_{3}} \frac{T_{4}}{\dot{Q}^{2}}\right]^{2} u^{2}(\dot{Q})
\end{aligned}
$$


246 In all the tests, we have calculated the evolution over time of the global thermal impedance of the sample.

247 Subsequently, since it is the only term affected by aging, we can deduce the evolution over time of the TCR 248 in the TIM.

249 Since the main objective is to evaluate the influence of aging on the TCR of the TIM, equal measurement 250 conditions are used both in temperature and pressure for all samples. The boundary conditions are the aging temperature, the aging time, the sample temperature during the test $\left(\mathrm{T}_{\mathrm{av}}\right)$ and the pressure applied to the sample during the test.

253 The initial values of the global thermal impedance of the 12 samples can be seen in Table I, whereas those 254 obtained after the aging process are presented below.

\begin{tabular}{|c|c|c|c|c|c|c|}
\hline & $\begin{array}{c}\mathrm{Z}_{\mathrm{g}(\mathrm{S}-\mathrm{P}-\mathrm{C})} \\
{\left[10^{-4} \mathrm{~m}^{2 \circ} \mathrm{C} / \mathrm{W}\right]}\end{array}$ & $\begin{array}{c}\mathrm{Z}_{\mathrm{g}(\mathrm{S}-\mathrm{I}-\mathrm{C})} \\
{\left[10^{-4} \mathrm{~m}^{2 \circ} \mathrm{C} / \mathrm{W}\right]}\end{array}$ & $\begin{array}{c}\mathrm{Z}_{\mathrm{g}(\mathrm{S}-\mathrm{G}-\mathrm{C})} \\
{\left[10^{-4} \mathrm{~m}^{2 \circ} \mathrm{C} / \mathrm{W}\right]}\end{array}$ & $\begin{array}{c}\mathrm{Z}_{\mathrm{g}(\mathrm{C}-\mathrm{P}-\mathrm{A})} \\
{\left[10^{-4} \mathrm{~m}^{2 \circ} \mathrm{C} / \mathrm{W}\right]}\end{array}$ & $\begin{array}{c}\mathrm{Z}_{\mathrm{g}(\mathrm{C}-\mathrm{I}-\mathrm{A})} \\
{\left[10^{-4} \mathrm{~m}^{\left.2{ }^{\circ} \mathrm{C} / \mathrm{W}\right]}\right.}\end{array}$ & $\begin{array}{c}\mathrm{Z}_{\mathrm{g}(\mathrm{C}-\mathrm{G}-\mathrm{A})} \\
{\left[10^{-4} \mathrm{~m}^{2{ }^{\circ}} \mathrm{C} / \mathrm{W}\right]}\end{array}$ \\
\hline $60^{\circ} \mathrm{C}$ & 4.35 & 4.79 & 4.62 & 1.96 & 2.26 & 2.32 \\
\hline $180^{\circ} \mathrm{C}$ & 4.29 & 4.74 & 4.61 & 1.85 & 2.38 & 2.24 \\
\hline
\end{tabular}

Table I: Initial values of the global thermal impedance as well as the uncertainty associated with the value obtained, as can be seen in Figs. 8 and 9. 


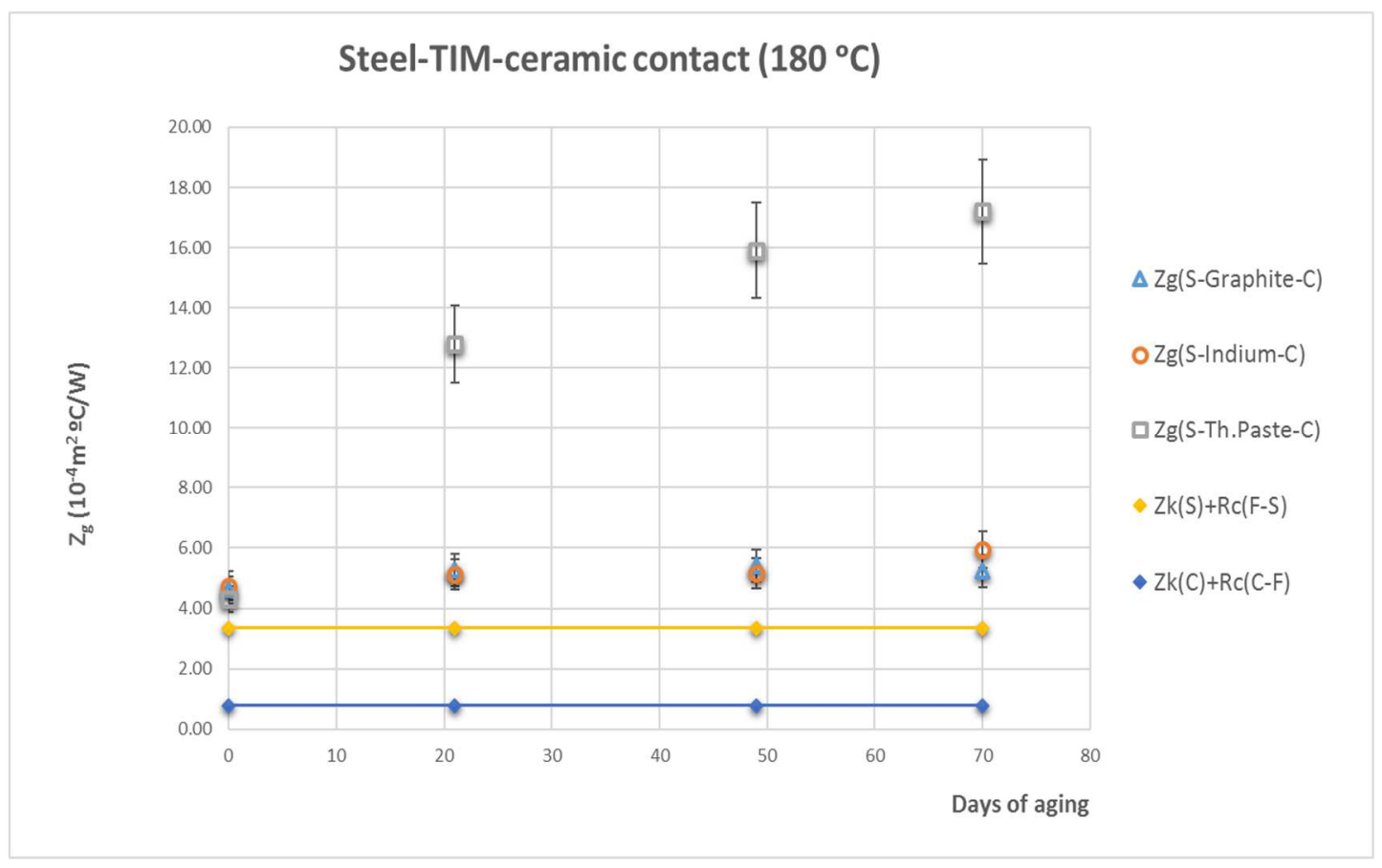

Fig. 8. Steel-TIM-ceramic contact $\left(180^{\circ} \mathrm{C}\right)$

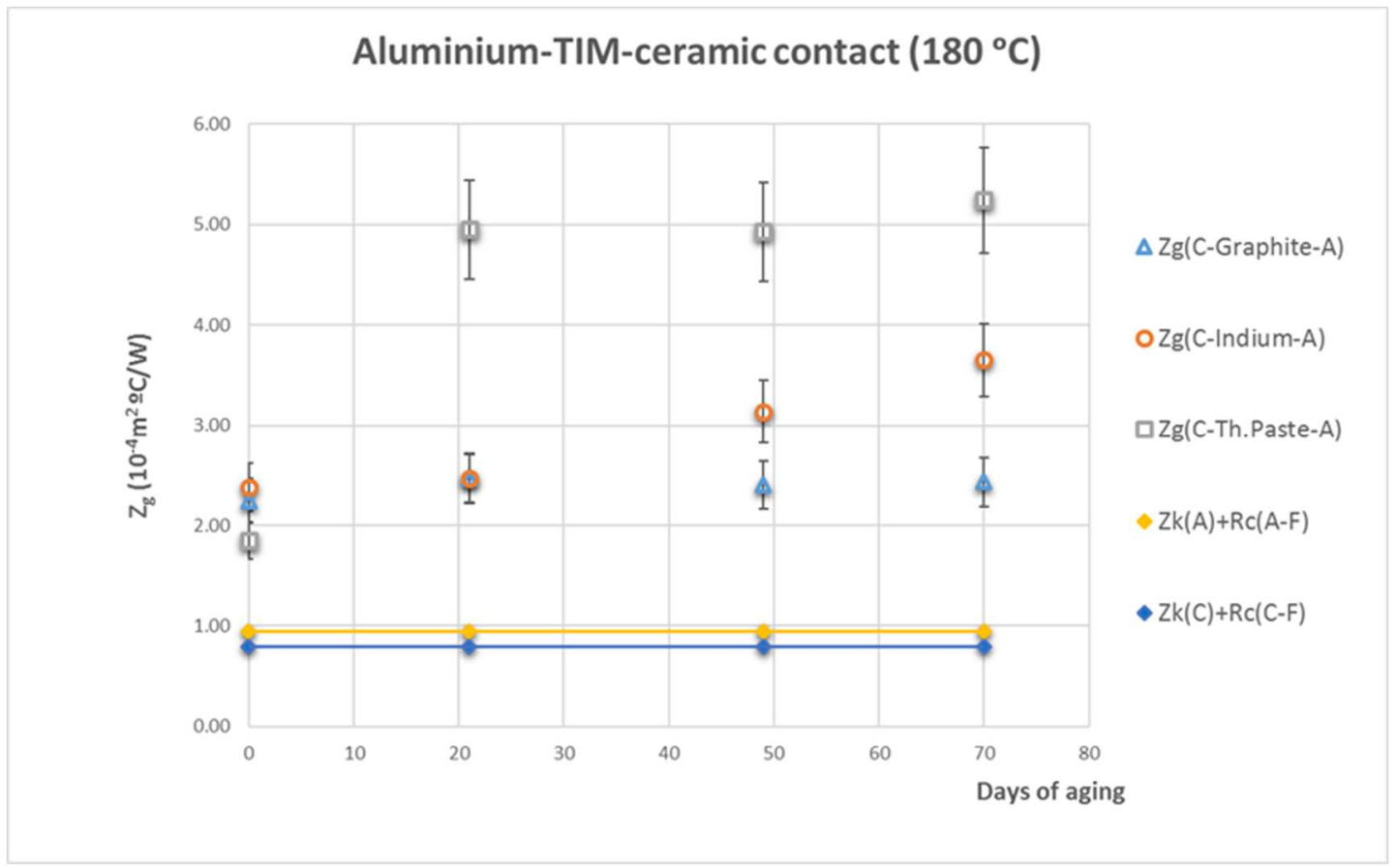

Fig. 9. Aluminum-TIM-ceramic contact $\left(180^{\circ} \mathrm{C}\right)$

In all the test, the global thermal impedance shows an increasing trend. In the case of the ceramic-pasteapproximately by $200 \%$. In the following periods, this trend continues but at lower rate. The total increase 
in the 70 days of exposure is $300 \%$. A slightly different pattern is obtained when the ceramic-pastealuminum sample (C-P-A-180) is tested, which presents an increase of $167 \%$ in the thermal impedance after 20 days of exposure. Thereafter, this value remains virtually constant, with a total increase of $183 \%$ at the end.

The global thermal impedance in the combination of thermal paste and steel increases more significantly than in the combination with aluminum. This may be due to the fact that aluminum is softer than steel, and therefore may present a larger effective contact area with the ceramic. Consequently, the area occupied by the holes and covered by the thermal paste is smaller in the case of aluminum, and the aging of the thermal paste might be less influential.

In the case of the ceramic-indium-steel sample (S-I-C-180), the observed increase is much lower than in the previous cases. The thermal impedance presents a total increase of $25.5 \%$ after 70 days of exposure. In the tests with ceramic-indium-aluminum sample (C-I-A-180), the increase is $50 \%$. Therefore, the performance of the indium is significantly better than that of the thermal paste.

The ceramic-graphite-steel (S-G-C-180) and ceramic-graphite-aluminum (C-G-A-180) samples have the best behavior at $180{ }^{\circ} \mathrm{C}$, with a total increase in the thermal impedance of $8.48 \%$ and $8.50 \%$ respectively after 70 days of exposure, which are even lower than the measurement uncertainty of the test bench (10\%). Therefore, it could be said that for long periods of more than 70 days of exposure to $180^{\circ} \mathrm{C}$, graphite is the material with greater performance.

\section{Aging with temperature of $60^{\circ} \mathrm{C}$}

The results of the thermal impedance after the tests with exposure temperature of $60^{\circ} \mathrm{C}$ are shown in Figs. 10 and 11. These figures report minute variations in the thermal impedance of the samples with steel (S-PC-60, S-I-C-60 and S-G-C-60), and also of the samples with aluminum (C-P-A-60, C-I-A-60 and C-G-A60). In fact, these variations are even lower than the mentioned measurement uncertainty. Therefore, it can be concluded that there is not significant change in the thermal impedance of the samples when they are exposed to a temperature of $60{ }^{\circ} \mathrm{C}$ for 70 days. 


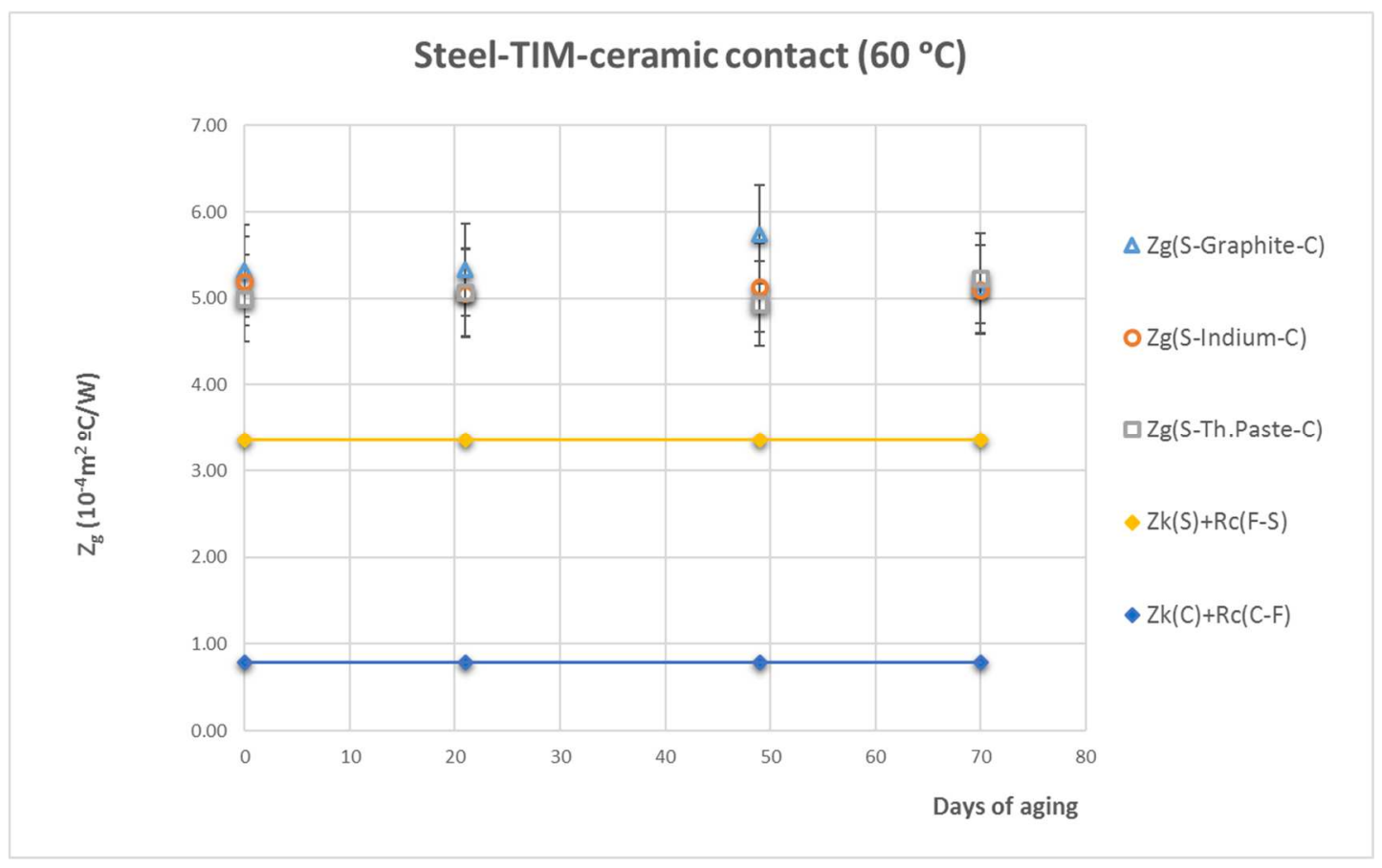

Fig. 10. Steel-TIM-ceramic contact $\left(60^{\circ} \mathrm{C}\right)$

296

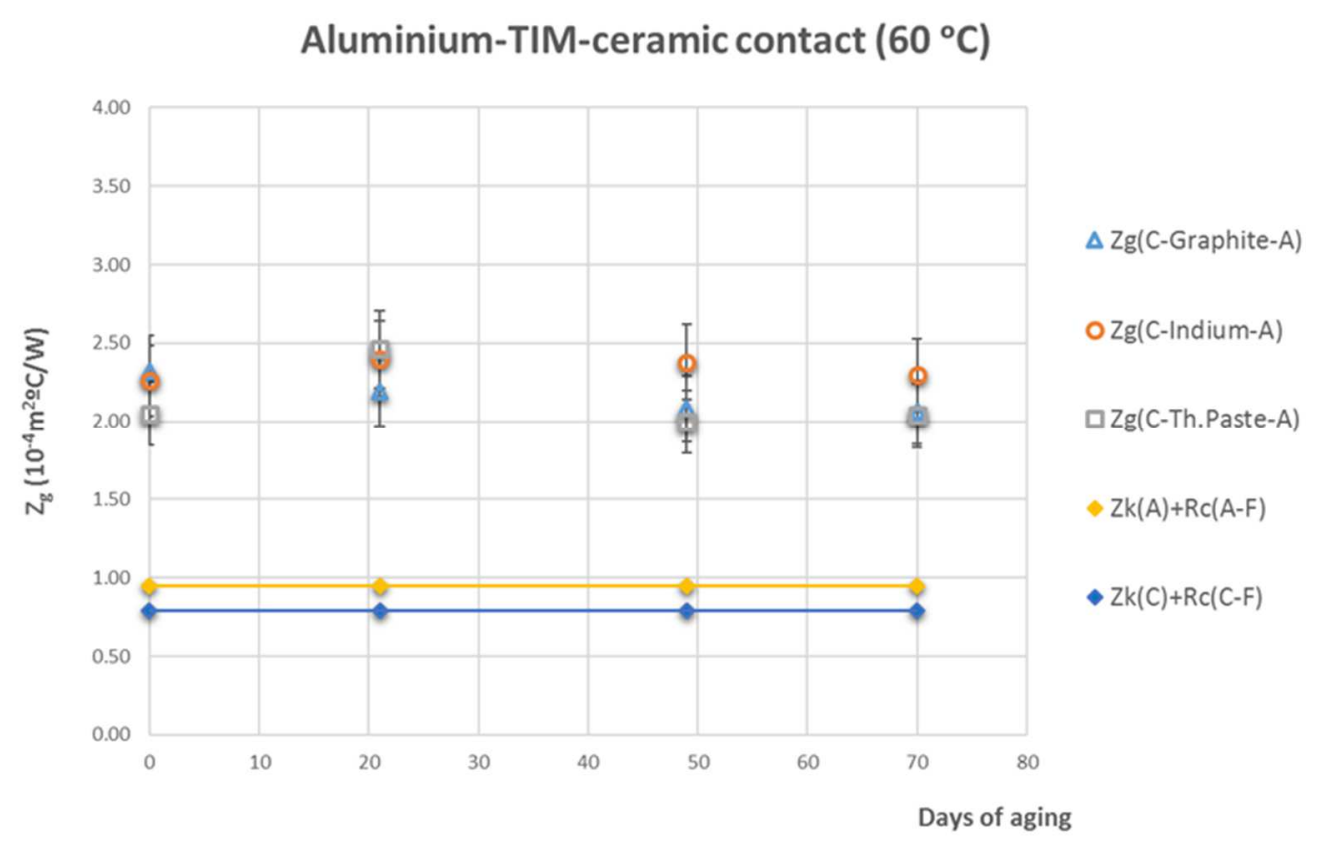

Fig. 11. Aluminum-TIM-ceramic contact $\left(60^{\circ} \mathrm{C}\right)$

CONCLUSIONS

301 An increase in the thermal contact resistance due to TIM degradation entails a decrease in the performance of a thermoelectric application. The test bench presented in this article is intended to evaluate the influence 
303

of this thermal contact resistance and serve as guide for the selection of the TIM best suited for each thermoelectric application. The tests show that the degradation of TIMs makes it necessary to measure the evolution of the thermal contact resistance over time for different temperature conditions.

This paper presents a methodology for evaluation of the influence of TIM aging on the thermal contact resistance. The testing conditions mimic those of a thermoelectric generator that absorbs heat from the hot surface of a steel chimney, and releases heat to the ambient through an aluminum heat sink. Two contacts arise from this configuration: steel-ceramic contact between the chimney and the hot face of the modules; and ceramic-aluminum contact between the heat sink and the cold face of the modules. For both, three TIMs have been studied (graphite, indium, and polysynthetic thermal paste) under aging temperatures of $180^{\circ} \mathrm{C}$ and $60^{\circ} \mathrm{C}$, so a total of 12 tests have been conducted.

The thermal impedance $\mathrm{Zg}$ is calculated experimentally, assuming that the only component of $\mathrm{Zg}$ affected by aging is the thermal contact resistance inherent to the TIM.

The results with aging temperature of $180^{\circ} \mathrm{C}$ report a significant increase in the thermal impedance due to aging for the three TIMs, although this increase is much more significant when thermal paste is used. Therefore, the use of thermal paste as TIM for the hot side of thermoelectric modules should be considered with caution, due to the experimentally-proven aging of this material at temperatures around $180^{\circ} \mathrm{C}$. As for the other two materials, graphite performs better against aging but indium offers better initial values of thermal contact impedance. In consequence, it is necessary to study whether the lower cost of graphite coming from its lower maintenance requirements (as indium must be replaced more frequently than graphite) counterbalances its higher initial thermal contact resistance compared to indium.

The tests at $180{ }^{\circ} \mathrm{C}$ carried out with steel indicate a greater increase in the thermal impedance compared to aluminum. This is explained by the larger hardness of steel, which entails a smaller effective contact surface and therefore a greater influence of the TIM. Thus, when the TIM degrades, it influences more significantly those materials with higher hardness, as is the case of steel compared to aluminum.

In the tests with $60^{\circ} \mathrm{C}$ of aging temperature, no variation in the thermal impedance has been found. Therefore, the use of thermal paste as TIM could be a good option at this temperature, as this material presents the lowest initial thermal contact resistance. 
Future research is planned to complete this study. In particular, new experimental analyses are expected for thermal characterization of TIMs after cycles at different temperatures and corrosive atmospheres.

\section{ACKNOWLEDGEMENTS}

The authors are indebted to the Spanish Ministry of Economy and Competitiveness, and the European Regional Development Fund for economic support to this work, included in the RTI2018-093501-B-C22 research project.

\section{REFERENCES}

1. P. Jaiswal and C.K. Dwivedi, International Journal of Innovative Technology and Creative Engineering IJITCE, (2011). http://ia800305.us.archive.org/34/items/IJITCE/IJTCE_May3.pdf Accessed 4 May 2011.

2. S. Narumanchi, M. Mihalic, K. Kelly and Gary Eesley, in ITHERM Conference Proceedings, (2008), doi:10.1109/ITHERM.2008.4544297

3. R. Prasher and CP. Chiu, in Materials for Advanced Packaging. ed. By D. Lu and C. Wong (Springer, 2017), p. 511.

4. I. Hu, M. Shih, G. Kao, in IMPACT'15 Conference Proceedings, (2015), doi:10.1109/IMPACT.2015.7365218

5. GK. Morris, MP. Polakowski, L. Wei, MD. Ball, MG. Phillips, C. Mosey and R.A. Lukaszewski, in IWIPD Conference Proceedings, (2015), doi: 10.1109/IWIPP.2015.7295991

6. J. Due and A. J. Robinson, Appl. Therm. Eng., 50, 455 (2013)

7. R. A. Sayer, T. P. Koehler, S. M. Dalton, T. W. Grasser, and R. L. Akau, in ASME 2013 Summer Heat Transfer Conference Proceedings, (2013), doi:10.1115/HT2013-17408

8. J.-P. Ousten and Z. Khatir, in EPE Conference proceedings, (2011), https://hal.archivesouvertes.fr/hal-00628876, Accessed 4 October 2011.

9. V. Khuu, M. Osterman, A. Bar-Cohen and M. Pecht, IEEE Transactions on Device and Materials Reliability, Vol. 9, № 3, 379, (2009)

10. R. Skuriat, J.F. Li, P.A. Agyakwa, N. Mattey, P. Evans, C.M. Johnson, Microelectron. Reliab. 53, 1933, (2013).

11. American Society for Testing and Materials, ASTM Standard D5470-06, (2006). 
12. J. Liu, H. Feng, X. Luo, R. Hu, and S. Liu, in Int. Conf. Electron. Packag. Technol. High Density Packag. ICEPT-HDP Conference Proceedings, (2010), pp. 116-120.

13. W. Zongren, Z. Weifang, Y. Mingyuan, Adv. Mater. Res., 337, 774 (2011)

14. R. A. Sayer, Heat Transfer Eng. (2015), doi:10.1080/01457632.2014.932553.

15. N. Goel, A. Bhattacharya, J.A. Cervantes, R.K. Mongia, S.V. Machiroutu, H.L. Lin, Y.C. Huang, K.H. Fan, B.L. Denq, C.H. Liu, C.H. Lin, C.W. Tien, J.H. Pan, in Electron. Packag. Technol. Conf. Proceedings Conference, (2008), doi:10.1109/EPTC.2008.4763637

16. M.C. Kumar Swamy and Satyanarayan, J. Electron. Mater. (2019), doi:10.1007/s11664-01907623-7

17. T. Sakamoto, T. Iida, T. Sekiguchi, Y. Taguchi, N. Hirayama, K. Nishio and Y. Takanashi, J. Electron. Mater. (2014), doi:10.1007/s11664-014-3165-7.

18. A. Rodríguez, J.G. Vián and D Astrain, Appl. Therm. Eng. (2009), doi:10.1016/j.applthermaleng.2009.03.005

19. A. Rodríguez, D. Astrain, A. Martínez, E. Gubía and F.J. Sorbet, J. Electron. Mater. (2013), doi:10.1007/s11664-013-2504-4

20. A. Rodríguez, D. Astrain, A. Martínez and P. Aranguren, J. Electron. Mater. (2014), doi:10.1007/s11664-014-3097-2

21. P. Aranguren, D. Astrain, A. Rodríguez and A. Martínez, Appl. Energy (2015), doi:10.1016/j.apenergy.2015.04.077

22. D. P. Bentz and K. R. Prasad. Rep. No. Building and Fire Research Laboratory (BFRL)-NIST 7401, NIST, Gaithersburg, MD. Publisher: U.S. Department of Commerce (2007). 